\title{
Evaluating the Load-Bearing Capacity of a Section of the Orenburg-Zainsk Main Gas Pipeline Using Static and Cyclic Loading Methods
}

\author{
Mekhrali M. Aliyev ${ }^{1, *}$, Sergey P. Zaytsev ${ }^{2}$,Zulfiya F. Ismagilova ${ }^{1}$, and Minsariya M. Bayburova ${ }^{1}$ \\ ${ }^{1}$ Almetyevsk State Oil Institute, 423450, Lenin street, 2, Almetyevsk, Russia \\ ${ }^{2}$ Almetyevsk Linear Production Department of Main Gas Pipelines, Gazprom Transgaz Kazan LLC, 423450, Bugulma trakt, \\ Almetyevsk, Russia
}

\begin{abstract}
This paper examines the operability of the Orenburg-Zainsk main gas pipeline, which has been in operation since 1971 and has various general defects, as well as specific defects such as internal corrosion-induced delaminations and blisters of various geometric shapes. The design parameters of the gas pipeline section and the characteristics of the pipe metal have been studied. Hydraulic tests were performed on the pipe fragments in the form of sample barrels to determine the load-bearing capacity in order to evaluate the operability of the gas pipeline. There were three types of sample barrels: those made from pipes with internal blistering and delamination, from pipes with invisible defects, and from emergency stock pipes. A cyclic test was performed on one sample according to the developed method. The theoretical analysis of the load-bearing capacity of the gas pipeline was performed according to the accepted design model.
\end{abstract}

\section{Introduction}

Today a large proportion of main gas pipelines has been in operation for more than 30 years. A number of factors, such as certain violations in the manufacturing technology and methods of construction and operation, can lead to impaired performance of gas pipelines.

The article discusses the Orenburg-Zainsk gas distribution main, which was put into operation in September 1971, as an example. With a glance to such a long operation period, the general condition of the main requires a detailed examination, including evaluation of the operability of individual sections of the linear part along with addressing practical issues related to loadbearing capacity and operational reliability of the pipeline as a whole.

Given the nature of the delaminations observed and resulting blisters on the sections of the gas pipeline in question, which are several kilometres long, the pipeline load-bearing capacity should be assessed in the framework of solving the following tasks:

- investigation of the possibility of the pipe steel delamination during manufacturing;

- study of the causes of blistering;

- study of the effect of resulting blisters and delaminations on the gas pipeline load-bearing capacity.

The Orenburg-Zainsk gas pipeline supplies regeneration gases from mercaptan removal units mixed with purified gas to Zainsk SDPP (State District Power Plant). This is a single-line buried gas pipeline constructed of $1,020 \times 16 \mathrm{~mm}$ pipes from a Swedish vendor used on the I category sections and 1,020x14 mm pipes fabricated in Germany and France - on the II category sections. The pipes are made of low-carbon low-alloy steel with a $0.18 \ldots . .0 .20 \%$ carbon content, with an ultimate strength of at least $520 \mathrm{MPa}$, a yield strength of at least $300 \mathrm{MPa}$, and an impact strength of $500 \mathrm{~kJ} / \mathrm{m}^{2}$ at minus $40^{\circ} \mathrm{C}$. The pipes are made of normalised sheet.

The main design specifications of the section under consideration: design pressure - 5.4 $\mathrm{MPa}$; allowable operating pressure $-3.4 \mathrm{MPa}$; pipeline diameter $-1,020$ $\mathrm{mm}$; and wall thickness $-14-16 \mathrm{~mm}$.
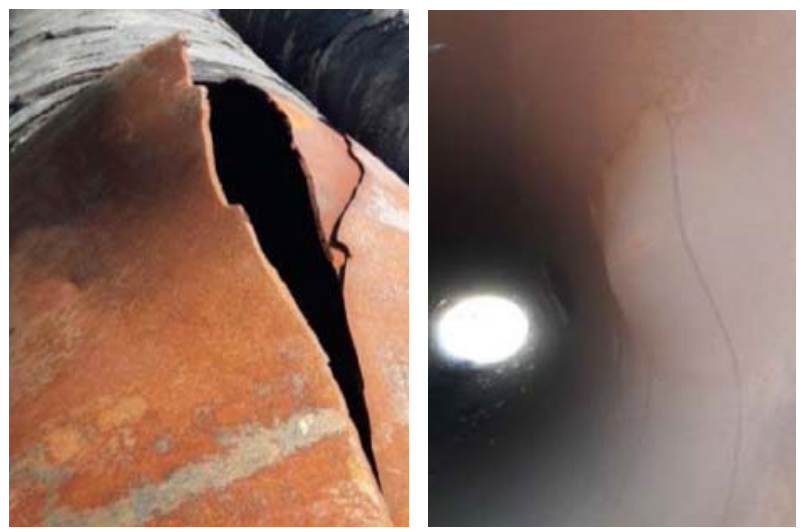

Fig. 1. Defects in the form of delamination detected after testing a full-size pipe with internal blistering.

In 2016, a comprehensive flaw detection of the main's $376-479.6 \mathrm{~km}$ section was performed. During the gas pipeline comprehensive flaw detection, 2,264 defects of different kinds were detected on the section [1]. Special attention was paid to such defects as blisters and

\footnotetext{
* Corresponding author: iiii.iskandar@inbox.ru
} 
delaminations having various geometric shapes and sizes detected during pig inspection and destructive hydraulic testing of a full-size pipe (Fig. 1).

\section{Causes of delaminations and blisters in the gas pipeline}

The cause of these blisters and delaminations can be attributed to the pipeline operating conditions at the initial stage, when the raw wet gas produced was fed directly into the pipeline. A jump in the gas pressure (from 12-13 $\mathrm{MPa}$ to the operating pressure) led to a decrease in the gas temperature and a change in the stress state of the pipe material. The temperature drop of the pipe's inner and outer surface reached $60^{\circ} \mathrm{C}$, which led to the delamination of the pipe steel structure and the loss of stability on the inner side as shown on the scheme (Fig.2).

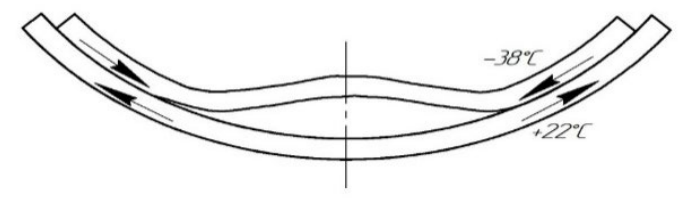

Fig. 2. Diagram of the pipe wall stability loss.

For this reason, a pipeline exposed to delamination cannot deliver performance required by the design.

To assess the load-bearing capacity of the gas pipeline sections that have such defects, we can take the first design model as a dome fixed on a yielding support ring. The cross section of the dome corresponding to the initial point of delamination should be taken as the yielding ring.

The design model is assumed in order to calculate the internal pressure that leads to collapse of the blisters and exhaustion of the pipeline load-bearing capacity.

After processing on the edge-banding and pipebending machines, the pipe wall roundness is insufficient, and the pipe diameter is by $0.5-1.5 \%$ less than required. To achieve the required diameter and the maximum roundness of the pipe, expanding is performed.

The calculations [2-4] show that in the case of a pipe with a $1,420 \mathrm{~mm}$ diameter and a yield strength of 500 $\mathrm{MPa}$ the maximum circumferential stresses in the pipe wall caused only by expanding exceed the yield strength of the metal. For this pipe, the sum of residual stresses after the pipe-bending machine and extreme circumferential stresses during expanding inside the pipe is $1.524 \sigma_{\mathrm{b}}$, where $\sigma_{\mathrm{b}}$ is the ultimate strength. The maximum circumferential stresses on the inner and outer surfaces of the same pipe are $1.254 \sigma_{\mathrm{b}}$ and $0.437 \sigma_{\mathrm{b}}$, respectively, that is, the maximum shear stresses inside the pipe wall and on its inner surface exceed $0.5 \sigma_{\mathrm{t}}$, since according to the Saint Venant-Tresca criterion, if $\sigma_{1}=1.254 \sigma_{\mathrm{b}}, \sigma_{3}=0$, that $\tau_{\max }=0.5(1.254-0) \sigma_{\mathrm{b}}=0.627 \sigma_{\mathrm{b}}$.
For this reason, such defects as micro-cracks and micro-delamination in the metal can appear on the inner wall surfaces of such pipes.

\section{Conditions for the formation of a blister inside the pipeline}

After the micro-delamination is formed in the pipe body under normal operating conditions without any significant temperature jump along the pipe wall thickness, the working pressure would help close these cracks. However, the temperature of pumped raw gas after reduction at the gas pipeline inlet decreases sharply, with the temperature delta approximately equal to $60^{\circ} \mathrm{C}$. Annular temperature stresses also show a jump that can be calculated using the formula [5]

$$
\sigma_{t}=\frac{E \alpha \Delta T}{3(1-v)\left(r_{2}-r_{1}\right)}\left[3 \tau_{1}-\frac{2\left(r_{2}^{3}-r_{1}^{3}\right)}{r_{2}^{2}-r_{1}^{2}}\right],
$$

where $E$ is the modulus of elasticity of steel; $E=2,1 \cdot 10^{5} \mathrm{MPa}$;

$\alpha$ - thermal expansion coefficient of steel, $\alpha=1,25 \cdot 10^{-5} 1 /{ }^{\circ} \mathrm{C}$;

$r_{1}, r_{2}-$ inner and outer radii of the pipe, respectively.

If $r_{1}=50 \mathrm{~cm}, r_{2}=51,4 \mathrm{~cm}$, the temperature compressive stresses of the inner section are equal to $\sigma_{t 1}=-105 \mathrm{MPa}$, and those of the outer section to $\sigma_{t 2}=$ 104,5 MPa.

Although the formula (1) is valid for thick-walled pipes, in the case of a sharp temperature drop inside the pipe, it can also be applied to thin-walled pipes. The deviation does not exceed $15 \%$.

Taking into account the conditions for the formation of delaminations during pipe manufacturing, blistering may be caused by a compressive stress $\sigma_{t 1}$.

Taking the area of the inner pipe section as a strip, we can calculate the critical stress sufficient for the loss of its stability by the formula [6]

$$
\sigma_{c r}=k \frac{E}{12\left(1-v^{2}\right)}\left(\frac{t}{a}\right)^{2},
$$

where $t$ is the thickness of the delamination, $t=7 \mathrm{MM}$;

$v$ - Poisson's ratio, for steel $v=0.3$;

$E$ - modulus of elasticity of steel; $E=2.1 \cdot 10^{5} \mathrm{MPa}$;

$k$ - ratio that depends on the blistering length and width, at $\frac{b}{a}=2, k=10$.

Substituting the parameters in formula (2), we obtain $\sigma_{c r}=106 \mathrm{MPa}$.

Thus, the temperature stress $\sigma_{t 1}=-105 \mathrm{MPa}$ can cause the formation of a blister. To this end, it is assumed that the internal operating pressure during the formation of a blister is taken up by the external layers of the pipeline up to the microlamination layers formed in the process of the pipe manufacturing. 


\section{The sequence of blister formation and collapse}

Figures 3 and 4 show the mechanism of the emergence of internal defects in the form of blisters in a gas pipeline under compressive and tensile stresses stemming from a temperature rise on the gas pipeline wall.

Figure 5 shows a scheme of the collapse of the blisters under the ultimate pressure during hydraulic testing.

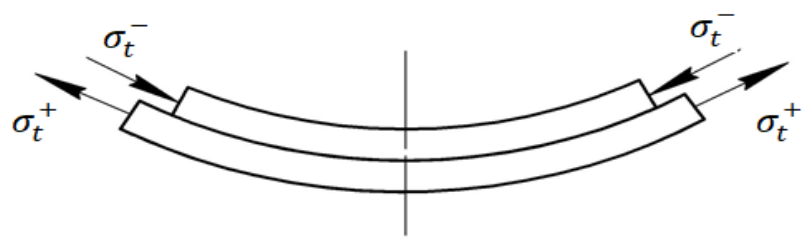

Fig. 3. Scheme of the emergence of compressive and tensile stresses on the gas pipeline wall.

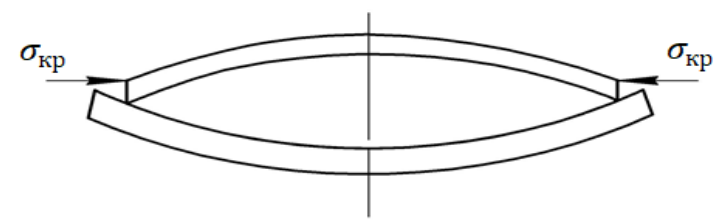

Fig. 4. Scheme of the formation of internal gas pipeline blisters.

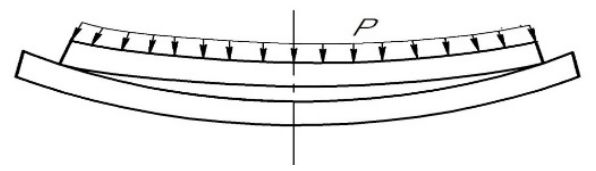

Fig. 5. Scheme of the collapse of the blisters by increasing the internal pressure in the gas pipeline.

\section{The change of the ultimate strength of steel in time}

Pipeline steel loses its original strength to some extent in the areas where delamination begins. It is quite a difficult task to detect exactly the point at which the destruction begins. To solve this problem, we can make samples cut from the areas marked by blistering. By testing these samples, we will reveal the proportion of impaired strength.

The load-bearing capacity of the pipeline with internal delamination and the formation of blisters, encountered in the case examined, can be found by means of hydraulic testing of barrels cut from the sections with such defects. Tests may be also performed on the barrels without similar visible defects. By comparing the results, we can indirectly obtain the ultimate strength of steel pipes with delaminations.

In the paper [7], the load-bearing capacity of two main gas pipelines after many years of operation was evaluated by testing the internal pressure of fragments of full-scale samples (barrels), as well as flat elements cut from the dismantled sections of pipes. The sample barrels had no visible defects, and no signs of delamination were found on them after destructive hydraulic pressure testing.

Calculations based on the membrane theory according to the barrels' geometric parameters, as well as the results of flat samples testing showed an insignificant deviation from the certified strength parameters.

The test performed on a full-size Orenburg-Zainsk pipeline with internal delaminations and blistering revealed a fairly significant decrease in the pipe's loadbearing capacity (Fig. 1) up to $9.2 \mathrm{MPa}$.

Hydraulic tests of pipe fragments in the form of sample barrels were performed to determine the loadbearing capacity for evaluating the operability of the gas pipeline (Fig. 6). There were three types of sample barrels:

- pipes from the emergency stock - collapse pressure was $16.8 \mathrm{MPa}$, which corresponds to an ultimate strength of $560 \mathrm{MPa}$, with $570 \mathrm{MPa}$ according to the certificate;

- pipes with invisible defects - pressure was $13.2 \mathrm{MPa}$, which corresponds to an ultimate strength of $440 \mathrm{MPa}$. Strength reduced by $23 \%$ over the period of operation; - pipes with internal corrosion-induced delamination pressure was 9.6 $\mathrm{MPa}$, which corresponds to an ultimate strength of $320 \mathrm{MPa}$. The decrease is $44 \%$ from 570 MPa.
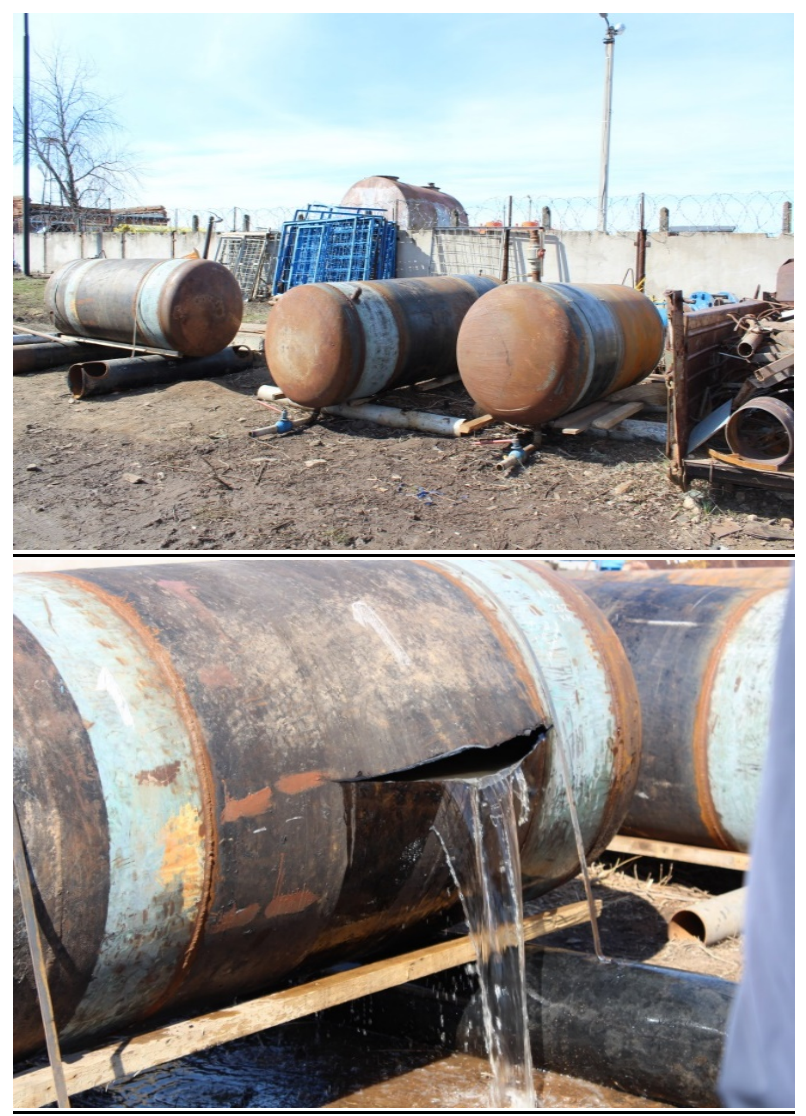

Fig. 6. Sample barrels before and after hydraulic testing.

To study the behaviour of the detected defects during the subsequent operation of the gas pipeline, a number of tests were performed on the defective pipe using the cyclic loading method. For this purpose, a barrel was made with a defect in the inner wall surface. An 
additional pipeline system with a pressure gauge and a tap was installed on the test barrel at a safe distance.

The pressure was initially increased to $6 \mathrm{MPa}$ using a hydraulic pump; after 24 hours it was lowered to $5 \mathrm{MPa}$; then after another 24 hours - to $4 \mathrm{MPa}$, etc.

At the next stage, the pressure was increased to 7 $\mathrm{MPa}$ and the test was repeated. After testing at $8 \mathrm{MPa}$ and $9 \mathrm{MPa}$, the sample was destroyed by a pressure of 9.5 $\mathrm{MPa}$.

Thus, the cyclic loading performed according to the described scheme did not affect the load-bearing capacity of the sample.

\section{Selection of the design model for in- pipe blisters with delamination}

Analysis of the external forms of in-pipe blisters, taking into account the absence of signs of deformation on the outer pipe surface, provides grounds for taking them as thin-walled shells with different dimensions in plan. In addition, we can also assume that the shells rest on yielding supports capable of moving horizontally as the shell is loaded with pressure.

For the shell taken as mentioned above, we will adopt the design model as follows (Fig. 7).

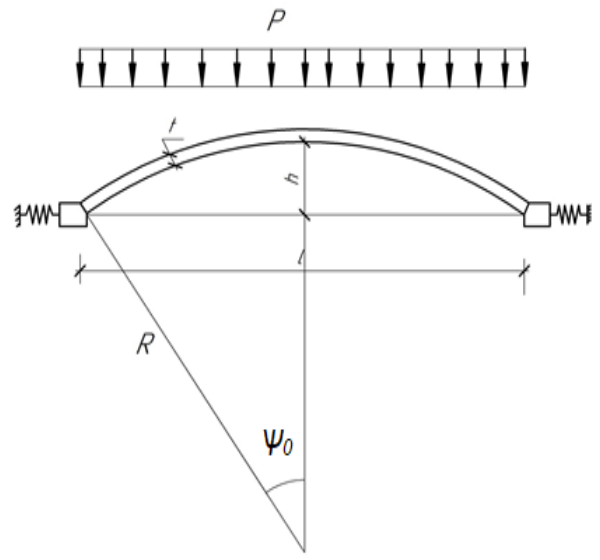

Fig. 7. The design model of shell loading.

The procedure for calculating such a shell can be found in [8].

The accepted assumption of the supports yield should be considered fair, since stresses are concentrated in this section, and it is the place where the maximum displacement will occur. Then the membrane theory can be applied in case of the assumed thin-walled shell.

The longitudinal bending moment is calculated by the formula

$$
M_{r}=\frac{p R^{2}}{2 k^{2}}\left(\cos \Psi_{0}-\frac{1-\cos \Psi_{0}}{\sin ^{2} \Psi_{0}}\right),
$$

where $k$ is the coefficient determined by the formula

$$
k=\sqrt{\frac{R}{t}} \sqrt[4]{3\left(1-v^{2}\right)},
$$

where $v=\frac{1}{6} ; R=30.13 \mathrm{~cm}, \mathrm{~h}=4 \mathrm{~cm}, \mathrm{t}=0,7 \mathrm{~cm}$.

According to Fig. 4, we obtain $\cos \Psi_{0}=$ $0.867, \sin \Psi_{0}=0.498, k=8.57$.

Taking into account only $M_{r}$, the dome strength condition is calculated as

$$
\frac{M_{r}}{W_{r}}=\sigma_{t},
$$

where $W_{r}=\frac{1 \cdot t^{2}}{6}$.

Substituting (3) in (5) we find the pressure at which the blister collapses

$$
p=\frac{2 \sigma_{n r} k^{2} t^{2}}{3 R^{2}\left(\cos \Psi_{0}-\frac{1-\cos \Psi_{0}}{\sin ^{2} \Psi_{0}}\right)} .
$$

Taking into account the metal fatigue in the support section and the stress concentration, we assume $\sigma_{n r}=$ $250 \mathrm{MPa}$, then $p=9.9 \mathrm{MPa}$.

If we assume that the inner pressure is taken only as an outer strip with the thickness of $\delta=7 \mathrm{~mm}$, the ultimate strength equal to the certified value, then the pressure leading to destruction will be

$$
p=\frac{2 \sigma_{\mathrm{cr}} \delta}{D}=\frac{2 \cdot 570 \cdot 0.7}{100}=8 \mathrm{MPa} .
$$

The difference between pressures calculated using the formulas (6) and (7) shows that at the time of the blister collapse and destruction of the pipeline, there is a short period of a cumulative effect of the blistering in the support zones and the base metal of the weakened cross section.

\section{Conclusions}

1. As a result of hydraulic testing of three sample barrels, the metal fracture pressures were found and the ultimate strength values of the pipe material were estimated.

2. Cyclic tests of the sample barrels with internal delamination were performed using the developed method.

3. The stresses leading to the formation of blistering and the pressures needed for these blisters to collapse were obtained with the use of the assumed design models.

4. Upon the analysis of theoretical and experimental studies, we can conclude that, since the destructive pressure (within 9.4-9.6 MPa) of pipes with internal delamination exceeds the operating pressure of 3.4 MPa 2.76 times, further long-term operation of the gas pipeline with such defects is possible.

\section{References}

1. A.V. Mitrofanov, N.A. Gafarov, B.V. Kichenko, A.I. Rezvykh, V.A. Polozov, Analysis of the causes and nature of corrosion damage in the initial period 
of the main gas pipeline operation. The Science and Research Journal of All-Russia Research Institute of Organisation, Management and Economy in Oil and Gas Industry (NTZh VNIIOENGa). Corrosion prevention and environmental protection, 10, 2-11 (1996)

2. V.N. Shinkin, Residual stresses during expansion of steel pipes. Molodoy Uchyony [Young Scientist], 20, 88-93 (2015)

3. V.N. Shinkin, Elastoplastic deformation of a metal sheet on three-roll mills. Molodoy Uchyony [Young Scientist], 13 (93), 225-229 (2015)

4. V.N. Shinkin., A. P. Kolikov, V. I. Mokrousov Calculation of maximum stresses in the pipe wall during expansion taking into account the residual stresses of the billet after the turbobend machine SMS Meer. Rolling, 7, 25-29 (2012)

5. Structural resistance: Textbook for colleges, Under the general editorship of the academician of the Academy of Sciences of the USSR G. S. Pisarenko, 4th edition reprint, revised and updated (Vyshcha Shkola [Higher School], Golovnoe Izdatelstvo [Main publishing house], Kyiv, 696, 1979)

6. Yu.A. Shimansky, Naval Structural Mechanics Handbook (Sudpromgiz, Leningrad, 251-252, 1958)

7. M.M. Aliev, R.R. Kantyukov, F.M. Mustafin, K.F. Ulshina, Evaluating the load-bearing capacity of two main gas pipelines after many years of operation by tensile strength test. Gazovaya Promyshlennosyt [Gas Industry], 12, 56-59 (2015)

8. B.N. Semochkin, Theory of elasticity (Publishing House of Construction and Architecture Literature, Moscow, 257, 1957) 